\title{
ECONOMIC EVALUATION OF MEDICAL TECHNOLOGIES: FROM THEORY TO PRACTICE-THE GERMAN PERSPECTIVE
}

\author{
J.-MATTHIAS GRAF VON DER SCHULENBURG \\ North German Center for Health Services Research HSR, University of Hannover, Germany
}

\begin{abstract}
This paper briefly describes the German health care system and the role of economic studies in medical technologies and drugs in a decentralized health care system like Germany's. It also provides a number of examples of studies which have been conducted recently in Germany and shows the variation of sponsors, study types, study perspectives and objectives of those studies. It concludes with an outlook on the future role of pharmaco-economic studies in Germany and the recently published German recommendations for conducting those studies. 1997 Elsevier Science Ltd
\end{abstract}

Key words-economic evaluation, pharmaco-economics, Germany, guidelines

\section{INTRODUCTION}

In recent years there has been a large increase in the number of economic evaluations of medical technologies, medical programs and pharmaceuticals. Many of the studies on medical programs and institutions, such as cancer prevention programs and the opening of a new transplantation center, have been financed by public grants. Studies on pharmaceuticals have been commissioned by pharmaceutical companies, in support of new or existing products.

However, an open question is if, how, and on whom economic evaluations had an influence on decisions. For a number of reasons economic evaluation studies seem to not play any role in decision making in medical care in Germany: (1) a recently published bibliography of economic evaluation studies concludes that most of the studies were done in the U.S. and Great Britain and that only $3 \%$ of all studies originate from European countries, Great Britain excluded (Backhouse et al., 1992); (2) decision makers in medical care, especially leaders of the powerful associations of sickness funds and office-based physicians, claim that they do not believe in the results of those studies if they are financed by suppliers of medical technologies or drugs; (3) those decision makers also criticize the methodological shortcomings of economic evaluation studies, namely the techniques to measure (indirect) cost and benefit; and (4) German health policy is dominated by macroeconomic distribution issues and a broad solidarity consensus rather than sophisticated consideration on efficiency in micro allocation of resources. Health politicians as well as health care administrators including directors of sickness funds will be re-elected not for their contri- bution to make the health care system more efficient but for their ability to please a majority.

Although these observations are not very encouraging for those interested in undertaking economic evaluations of medical services, studies are done in Germany and their number increases at an exponential rate.

To clarify the real benefit of economic evaluations in Europe is not easy (Drummond et al., 1993), due to the decentralized and complex nature of the many faceted health care systems in the European countries (admittedly, that the U.S. health care system is even more complex). In this paper some information is provided for a better understanding of who is financing those studies and for what reasons in Germany. In addition the current and future role and potential influence of economic evaluation studies on decisions made in Germany are discussed.

This paper will not provide a general overview of the German health care system or the current health policy debate in Germany (Hoffmeyer and McCarthy, 1994; Schulenburg, 1994). It will also not describe different methods employed in economic evaluation studies in medical care (Sloan, 1995). The information can be found somewhere else in more detail and depth than it can be provided here.

The purpose of this paper is (1) to describe economic evaluation studies of medical technologies and drugs in Germany; (2) to provide information about the acceptability of and knowledge about economic evaluation techniques of various decision making institutions in medical care; (3) to assess the potential impact of economic evaluation studies in general and pharmaco-economic studies in particular on decisions in the past and in the future in 
Germany; and (4) to compare the purpose of economic and pharmaco-economic studies in Germany with other European countries.

In particular, the paper intends to clarify how results of economic evaluation studies are used by public agencies and private organizations to make decisions about pricing, coverage, co-insurance, and treatment guidelines.

The paper intends to present as much information as possible on economic evaluations and their impact on decision-making in medical care in Germany. Although it is an empirical study it does not present quantitative data but rather qualitative information. Survey information on the use of economic evaluations in Germany is not available yet and difficult to gather. For instance, sending out a questionnaire to decision makers in medical care in Germany would not provide much information because decision makers would not reveal information publicly on a highly sensitive political issue such as decision making processes on resource allocation. Empirical information presented in this paper is based on the experience of the health economic group at Hannover University and the Center of Health Services Research (HSR), which participated in many economic evaluation studies.

In addition, a number of informal interviews with representatives of various organizations financing those studies (the Federal Department of Health, the Federal Department of Research and many pharmaceutical companies) were conducted. However, interpretations of findings are more the subjective expert opinion of the author than scientific statements.

We are unable to put together any statistics about the number of studies conducted in Germany, their characteristics, resources devoted to those studies, study objectives or their impact on health care decisions. To collect information, informal interviews were conducted by the Hannover team. Most respondents indicated their statements as personal views rather than official positions of their institutions.

This chapter on Germany is organized as follows. The second section briefly describes the German health care system. The third discusses the role and influence of health economic research in general and economic evaluation studies in particular by focusing on a number of examples. In the fourth section I evaluate objectives, acceptability and influence of economic evaluations. The fifth section analyses the quality of economics evaluation studies (EESs) in Germany. Finally, some conclusions are drawn for the future role of economic evaluations in Germany.
DECENTRALIZED PLANNING, CENTRALIZED COST CONTROL AND NEED FOR ECONOMIC EVALUATIONS

To understand decision making in the German health care system the following facts must be known.

About $90 \%$ of the German population have comprehensive complete coverage through one of the 650 sickness funds (Krankenkassen). The rest either have private insurance coverage $(9 \%)$, are covered by public programs $(1 \%)$, or are uninsured $(0.2 \%)$. All employees earning less than DM 6.000 per month (in 1996) have to be insured by a sickness fund.

The sickness funds are financed by pay-as-you-go contributions, expressed as a percentage of earned income (on average $13.0 \%$ in West and $12.8 \%$ in East Germany in 1995; see Bundesministerium, 1995). Half of the contributions are paid by the employee and the other half by employer. Coverage of employees by a sickness fund extends to all dependent family members (spouse and children without own income). Every sickness fund calculates its own contribution rate and adjusts its every year according to its own expenditure trends. But a risk-adjustment transfer system employing the criteria of age, gender composition and income was implemented in 1994 to avoid risk selection of funds.

Sickness funds pay all prescribed drugs, except those on a negative list. The 1993 health care reform act required that a positive list has to be developed by a newly founded Drug Institute for the statutory health insurance (Arzneimittelinstiut der Gesetzlichen Krankenversicherung). The positive list should list all drugs which may be prescribed at the expense of sickness funds and should also compare the cost of alternative drug therapies. Economic considerations should also be taken into account to incorporate a drug in the positive list. A first proposal published by the Drug Institute was not accepted by the Minister of Health and strongly criticized by the pharmaceutical industry. The Minister has dismissed the Drug Institute, so it is uncertain whether a positive list will ever be implemented on a federal level or how restrictive it will be. The General Medical Council of Berlin (Ärztekammer Berlin) has published its own negative list recently.

Decentralized decision making is a key element of the system. In principle the sickness fund associations on local. state and federal level negotiate all terms of health service provision and fees and hospital payments with the individual hospitals and the respective associations of the insurance doctors (Kassenärztliche Vereinigungen). dentists (Kassenzahnärzliche Vereinigungen), hospitals (Deutsche Krankenhausgesellschaft) and other providers. 
However, this decentralized decision process was abandoned by the latest health insurance reform. Global budgets were set for physician expenditures, drug expenditures and hospital payments for a transition period of three to four years. After 1996 full competition between sickness funds will be implemented and decision making will be decentralized again.

Sickness funds have only very limited power to influence the decisions of office-based physicians directly, because office-based physicians are reimbursed by their insurance doctors' association which is compensated by the sickness funds. However, sickness funds influence physicians' behavior by a number of indirect measures.

The German health care system is in a transition period from the uniform sickness fund system where every fund offers the same benefit package with given insured to a competitive insurance system with a multiple choice of funds and benefit packages for the insured.

On the supply side the German system is characterized by a strict separation of ambulatory care provided by office-based insurance doctors (Kassenärzte; doctors who are members of the insurance doctors' association) paid by fee-for-service and hospitals paid by per diems. Office-based dentists (Kassenzahnärzte) are paid by fee-for-service as well. After 1996 office-based physicians will be paid partly by the number of patients (Ordinationsgebühr). Hospitals will be paid by fixed fees, diagnosis related groups (Fallpauschalen), and flat fees for certain treatments (Sonderentgelte). Hospitals will be able to provide outpatient services. Office-based physicians will be able to provide services traditionally done by hospitals.

Many new ways of paying providers, providing care, and increasing system efficiency are currently discussed in Germany, and some proposals will be studied in regional case studies. For instance the firm-based funds (Betriebskrankenkassen) have started a project in Berlin in 1996, in which networks of physicians are paid with budgets covering not only physician fees but also the cost of prescribed drugs and hospital stays of the patients of these physicians. Hospitals have an option since 1995 to be paid by patient management categories instead of per diems, and new communication networks between medical suppliers are tested to improve information flow.

The German government has tried to contain health care cost by a number of cost-containment laws in the past: 1977, 1982, 1983, 1988 and 1993. The sixth and seventh reform will be in 1996 and 2000. To guess how the health care system will be modified by these reforms, the recent proposals by the Council of Scientific Advisors to the Federal Ministry of Health (Sachverständigenrat der Konzertierten Aktion im Gesundheitswesen) can serve as a guide. It proposes: better documentation of patient careers and transparency of service provision; outcome orientation of the whole health care system and the payment system; reduction of capacities (oversupply of physicians and hospital beds); more autonomy to individual sickness funds to contract selectively with suppliers; more freedom to insured to select insurance coverage; enlarged tax base for sickness fund contribution to entire income instead of working income only; and an additional contribution of DM 180 for spouses who do not work and do not take care for elderly. Spouses and children without own working income are covered currently free of charge by the sickness fund of the insured.

These trends towards more competition and outcome oriented remuneration schemes have changed the demand for studies about the economic consequences of medical interventions and programs. The government and medical societies want to provide guidelines for efficient health care by developing positive lists, treatment guidelines and recommendations for managing patient careers. Sickness funds change from a pure financier of medical services to a buyer of services. Hospitals and hospital departments can not rely on full reimbursement of their cost anymore, but have to get along with budgets, diagnosis group payments and flat fees for services. The capacity of hospital beds and new regulations allowing profits in the traditionally non-profit hospital sector will increase competition among hospitals drastically and will make economic considerations worthwhile. Officebased physicians do care much more about the cost of prescribed drugs due to the drug budget and new incentive schemes than they did in the past.

The recommendations of the Council of Scientific Advisors will increase the need and the ability to conduct economic evaluation studies. Until now, sickness funds did not collect individual data of their insured. This will and has to be changed to stay competitive and calculate the risk-adjustment payments. It will also allow a better data base for cost of illness studies and cost of treatment evaluations. The Council calls for an outcome orientation of medical care. Outcome indicators are mortality and survival rates, work sick-leaves, and some generally accepted medical indicators. An indicator system has to be developed which does also include economic outcome indicators, quality of life measures, and patient satisfaction data. Outcome measurement is one of the crucial problems of economic evaluations. Cost comparison alone is only sufficient if alternative treatments lead to same outcome, or the treatment with lower cost is considered superior. However, this is normally not the case.

Until now, competition between sickness funds and hospitals was restricted. That has changed. Sickness funds and hospitals try to develop a specific profile and goodwill to be more successful in competing against other sickness funds and other 
hospitals. A reduction of capacities in hospital and ambulatory care requires definition of adequate capacities and selective contracting of sickness funds with suppliers. Until now, sickness funds covered treatments of all hospitals and office-based physicians. Economic evaluations can provide valuable information to make those decisions.

Expecting those major changes in medical care is one of the reasons that suppliers of medical services as well as decision makers in hospitals and sickness funds have an increased interest in economic evaluations.

\section{OBJECTIVES OF ECONOMIC EVALUATION STUDIES IN MEDICAL CARE}

Interest in economic evaluation studies in medical care

Is the rapidly increasing number of economic evaluations of health services a demand pull or a supplier push movement? In other words, do those who finance the research in this field, mainly pharmaceutical companies, and conduct, mainly health economic research institutes, those who push for more economic evaluations in medical care by publishing and promoting economic evaluations of medical technologies and pharmaceutical products? Or, do sickness funds, health insurers, physicians' associations, hospitals and governmental agencies ask for economic evaluations to help on decisions about product licensing, price setting, co-payments and inclusion in drug positive lists or treatment guidelines?

At the moment, research on economic evaluations in health care is mostly initiated by suppliers of medical goods. The competition between drug companies works as an additional strong incentive to conduct those studies. To develop a special profile as a company providing also economic information on drug therapy seems to be a valuable marketing tool. Pharmaceutical companies have also discovered economics as a topic for physician education programs. Some pharmaceutical companies offer management seminars to physicians and teach physicians how to explain to the payers why more costly therapies may be cost saving in the long run. Those arguments are also used to defend hospital budgets in negotiations with sickness funds.

On the "demand side" is a lot of skepticism concerning health economic studies. Economic evaluation studies are often criticized. The arguments include: pharmaco-economic studies are always in favor of the product of the company financing the study; they do not reflect real medical practice if based on clinical trials with a selected patient population and protocol driven procedures; methodological problems to estimate indirect cost (e.g. productivity losses caused by illness and long-term nursing cost at home and at nursing facilities) and quality of life are not solved; the methods are not standardized, so that the method is chosen which makes the study drug look best from an economic point of view; and economic evaluation studies do not help allocating resources efficiently because they provide a partial view of the complex health care system.

In addition, one has to admit that many factors including the professional skill of physicians, patient characteristics, health insurance coverage and special characters of the institutions where patients are treated influence the economic outcome.

Health economics research in general is a young field and not well accepted in Germany. Health economics is taught at very few universities (Cologne, Hannover, Ulm). Organizations and companies interested in health economics have difficulties in employing trained health economists. The lack of health economic teaching and research at German universities may surprise outside observers, because most public health policy debates are driven by economic considerations and are dominated by the question how can we maximize outcome of medical care under given budget constraints. The budget constraints are even set by the Social Security Law which demands stability of the sickness funds' contribution rates. In the past few years this condition could be met by mutual efforts of the sickness funds and suppliers' associations to cut fees, set budgets and limit the availability of services. Economic evaluation studies were not needed and not available to steer the system.

However, the health insurance system in Germany is changing due to the pro-competitive reforms. Sickness funds have shown an increased interest in economic evaluations recently, and some participate in economic evaluation research activities and provide data.

Table 1 provides some information about the various types of health insurers and their current interest in and knowledge of economic evaluation studies in medical care. As mentioned in the second section, the majority of the population is covered by sickness funds. Sickness funds belong to different types of funds. Each has its own organizational structure and is represented separately by state and federal associations. Private health insurers are presented by a federal association. The "market shares" of the different types of coverage are quite different in West and East Germany. Thus, the influence of economic evaluation studies on decision making varies from region to region. In addition, some state insurance doctors' associations are more open to economic evaluation of medical services than others.

The local sickness funds (Ortskrankenkassen) have the largest market share. The federal association of local sickness funds is now employing some experts who have an interest in economic 
Table 1. Health insurers' associations and their knowledge about EESs

\begin{tabular}{|c|c|c|c|}
\hline & $\begin{array}{l}\text { Market share in \% } \\
\text { West/East Germany } \\
\quad \text { (in 1994) }+\end{array}$ & $\begin{array}{l}\text { Experts employed, } \\
\text { interest in economic } \\
\text { evaluation }\end{array}$ & $\begin{array}{l}\text { Acceptance of economic } \\
\text { evaluation studies }\end{array}$ \\
\hline Local sickness funds & $37.0 / 53.8$ & Some, little & Increasing \\
\hline Firm-based funds & $\begin{array}{c}11.3 / 7.4 \\
29.7 / 28.8\end{array}$ & $\begin{array}{l}\text { Special department, some } \\
\text { None, little }\end{array}$ & $\begin{array}{c}\text { High } \\
\text { Low, disapprove societal perspective }\end{array}$ \\
\hline Substitute funds & & & of economic evaluations \\
\hline Farmers/sailors/craftsmen funds & $8.6 / 28.5$ & None, none & No interest \\
\hline Private health insurance & $10.7 / 1.6$ & None, none & No interest \\
\hline Other coverage & $2.5 / 1.0$ & None, none & No interest \\
\hline No coverage & $0.2 / 0.1$ & & \\
\hline
\end{tabular}

Source: Bundesministerium, 1995

evaluations. The local sickness funds are willing to participate in economic evaluation projects.

Some companies have their own sickness funds, so-called firm-based funds (Betriebskrankenkassen). In the past firm-based funds showed the largest interest in management innovations in medical care. Because of their link to special companies they have also a broader view of the cost caused by diseases. Companies have not only an interest to provide medical care to their employees at reasonable cost, but also an interest to reduce the indirect cost caused by sick-leaves. Firm-based funds are also the first ones conducting a project in the city of Berlin to study managed care and preferred provider concepts. The federal association of firm-based funds has a new department for economic projects in medical care headed by a health economist. The firm-based funds have participated in the past in economic evaluation research projects.

The substitute funds (Ersatzkassen) operate nationwide and therefore have a lower regional market share than the other funds which operate only in one region or for one company. The substitute funds are traditionally seen as a substitute for the "standard" health insurance offered by the local and the firm-based funds. In the past, they covered mostly white collar workers. Most legal differences between local sickness funds and firm-based funds on the one hand and substitute funds on the other hand were removed by the last two health insurance reforms. However, one difference remains: the board of directors of the local and firm-based funds is elected and supervised by representatives of the insured and their employers. The board of directors of the substitute funds is elected and supervised only by representatives of the insured. Substitute funds show not only very little interest in economic evaluations, but also criticize the increasing interest in economic evaluation studies. They also disapprove explicitly of the inclusion of cost which is not covered by sickness funds and of quality of life considerations in economic evaluation studies. The inclusion of indirect cost or a societal perspective, the substitute funds argue, is not in line with current cost-containment efforts and in the interest of the sickness funds because it will increase the demand for health services.
All other institutions providing health expenditures coverage have no experience and no interest in economic evaluations of medical services and goods. The market share of private health insurers is too low to influence resource allocation in medical care, and the other sickness funds mainly follow the policy of the larger sickness fund groups.

To conclude, those financing health care have currently only little interest in economic evaluation studies, but the interest is growing. If the acceptability and the need is so low, why are "suppliers" (pharmaceutical companies, medical technology companies) conducting economic studies?

\section{Objectives of economic evaluation studies in medical} care

Some studies are used for in-house purposes, such as price setting, setting research priorities and predicting market opportunities.

Most economic evaluation studies are, however, done to lower sales barriers in the market for pharmaceutical products and medical devices or to support strategic goals of producers of medical goods. Economic evaluation studies are not requested by law or any governmental or sickness fund organization yet. To provide an idea of the many reasons for doing these studies in Germany, we have reviewed the studies conducted by the Hannover health economic research group, and have tried to recall what major reasons have been mentioned by the sponsoring institution to order the study. Unfortunately, it is not possible to provide a structured list or a ranking of the reasons known because we do not have an overview of all studies which have been conducted in Germany.

Table 2 presents an unordered list of reasons detected by us. For each reason an abbreviation (P1-P10) is given, which is used in Table 6.

Some additional remarks can be helpful to understand the 10 reasons or problems addressed in the study which are listed in Table 2 . The first and the third reason are the most common ones for pharmaco-economic studies. New drugs and medical technologies are in many cases more expensive than their older substitutes (P1). Sellers of more expensive goods have to show that the extra costs are worth the money. Economic evaluation studies are 
Table 2. Reasons for conducting economic evaluations

Reason or problem addressed in the study

Drug or technology is more expensive than competitor Research has to be intensified and needs public support Drug or technology is new or will be launched in near future

Drug or technology is an established therapeutical tool, but an additional marketing topic is needed

Disease does not get enough public attention or is not well presented by patient association

Risk of being excluded from positive list or placed on negative list

Non-prescription status or prescription drug status is $\quad$ P7 desired

Total cost of disease or the long-term burden of improper treatment are unknown

Economic evaluation is part of global research strategy

Try to win battle with economic arguments after having lost medically

conducted to show either in cost-cost studies that higher cost of the innovation are offset by savings because of less side effect treatments or follow-up treatments or in cost-effectiveness or cost-utility studies that the cost-outcome ratio is better for the innovation than for the older substitute

Economic evaluations are normally only one piece of a broader research program for new products (P3). That is why it is difficult to isolate the impact of an economic evaluation study on decision making. It is the same with clinical studies where it is difficult to show the impact of a single clinical trial on the decisions of institutions and prescribers.

The second, fifth, seventh and eighth reasons listed in Table 2 address the societal perspective of diseases. As mentioned above, some sickness funds do not accept the societal view taken in economic evaluation studies. They do not even accept the inclusion of nursing costs which are covered by the newly founded social care insurance (Soziale Pflegeversicherung) financing long-term care. The second reason $(\mathrm{P} 2)$ is not an obvious one. Medical research is mostly done by pharmaceutical companies in fields where a profitable market is expected. Some research is co-financed by public grants if this research would not otherwise be undertaken, because the future market is too small or a marketable outcome of research is not expected in reasonable time. However, some diseases get less attention because there are no patient pressure groups or they are not taken up by the media.

A pharmaceutical company had asked the Hannover group, for instance, to conduct a cost of illness study on Alzheimer disease to show the societal burden of this disease and to stimulate public support for research (Schulenburg et al., 1995a). The German telephone company, Telecom, conducted a study on the current and future cost and benefits of telemedicine to get the European Union to include telemedicine in their research program (Schulenburg et al., 1995b). Telecom has a research institute, DeTeBerkom, located in Berlin, which has applied successfully for grants at the European Union and the German Federal Ministry of Health.

Health economics distinguish between direct and indirect cost and benefits. The distinction between direct and indirect varies due to the differences in financing medical care. In German studies direct cost are usually those costs which are covered by sickness funds and private health insurers. All other costs are denominated as indirect cost, even those expenditures for nursing and medical services not covered by the benefit schedule of the sickness funds. This has to be taken into consideration if results from German studies are compared with those conducted in other countries. For many diseases and many treatments the indirect cost and indirect cost effects are much larger than the direct cost. Disregarding indirect cost and benefits is leading to an underestimation of the full societal cost and benefit associated with a treatment. To standardize the estimation technique of productivity losses caused by sick-leaves and time spent to receive health care or to care for others, the recently published German guidelines for economic evaluation studies propose to take the average gross wage of German employees including all benefits paid by the employers (Hannover Konsens, 1996).

A study recently conducted was done for the seventh reason. It is a cost-cost study on smoking cessation gums. The drug is not covered by sickness funds, because it is on the negative list, but may only be bought with a prescription. The company believes that sales will increase if the drug is prescription free because to visit a doctor is burdensome, and some people do not like to discuss their addiction with someone else because it is publicly stigmatizing. The company applied at the German drug administration for (Bundesamt für Arzneimittelprüfung) a prescription free status for the drug. The administration asked for an economic analysis showing that this will increase its consumption and by this reduce the societal costs of treating diseases caused by smoking.

Marketing goals are reflected by the fourth and the sixth reason. whereby either prescribers or public agencies are the targets. Pharmaceutical companies successfully incorporate economic topics and economic evaluation studies in their teaching program for physicians and hospital administrators. One company selling drugs to treat peripheral arterial occlusive disease has changed its marketing program totally for some years. The main topic of workshops became economic questions associated with the disease and alternative forms of treatment.

A positive list is currently being discussed in Germany. Being excluded from the positive list means the drug cannot be prescribed on the expenses of sickness funds. However, the Ministry of Health, the health policy experts of the opposition party (Social Democratic Party) and the Drug Institute disagree about the size and usefulness of a 
positive list. The Minister of Health wants a very comprehensive one, the others a more restrictive one. Economic evaluation studies have been conducted to reduce the risk of being excluded from the list, because the Drug Institute is required to take economic considerations into account too. As of early 1996 a positive list has not yet been imposed.

Many economic evaluation studies are conducted in Germany as a part of an international and global research program on a drug or new medical technology (P9). A multinational perspective in market strategies and the development of new products became more common in the past few years, because the national markets are interrelated. For instance, price setting for drugs in one European country influences the price setting in other countries. Large price differences are not only disapproved by public health policy, but also lead to re-imports, e.g. of German exported drugs back to Germany. However, it is quite difficult to develop a common framework for a multinational economic study because the perspective, payment systems and the acceptability varies among countries. For example, computer models developed in the U.S. employing diagnosis related groups are not easy to employ in Germany, because physicians and hospitals are paid differently and the whole system of delivering and financing care is different. There is also no general answer to the question if charges or true cost should be taken to estimate the costs and monetary benefits of a drug or medical technology.

The last reason mentioned in Table 3 (P10) is certainly not acceptable from a scientific point of view, and does therefore not deserve further consideration in this paper.

In the next chapter we will analyze the objectives. acceptability and influence of economic evaluations in medical care by referring to concrete examples of those studies.

\section{ACCEPT ABILITY AND INFLUENCE OF ECONOMIC EVALUATION STUDIES: GENERAL JUDGEMENT AND SPECIFIC EXAMPLES}

Acceptability of economic evaluation studies in medical care

Most economic evaluation studies in medical care are financed by pharmaceutical companies. Research of some non-pharmaceutical economic evaluations is paid by governmental institutions. For instance, the Center for Health Services Research (HSR). Hannover University, has conducted an economic evaluation study on the transplantation program in Hannover which was financed by the Ministry of Health and the Ministry of Research (Greiner and Schulenburg, 1995: Nagel et al. 1993). Another study was on telecommunication in medicine ordered by DeTeBerkom, Berlin, a subsidiary of the German governmental owned national telephone company (Schulenburg et al., 1995b).

The perspective of economic evaluation study is not uniform in Germany. Some studies try to influence decisions of governmental institutions, such as the Ministry of Health, the Federal Drug Administration, or the Drug Institute for Statutory Health Insurance. Others are targeted at professional organizations or hospitals. The ultimate goal of most pharmaco-economic studies is to influence the demand for drugs and the prescription behavior of physicians. Hospitals, health insurers and patients have to be convinced that the benefits overcompensate the cost of treatment. The most important institutions are listed in Table 3. The table also provides some information about the tools,

Table 3. Intended audiences of economic evaluations

\begin{tabular}{|c|c|c|c|}
\hline Organizations & $\begin{array}{l}\text { Main decision on resource } \\
\text { allocation }\end{array}$ & Main objective & $\begin{array}{l}\text { Experience with economic } \\
\text { evaluations }\end{array}$ \\
\hline Federal Ministry of Health & Setting legal framework & $\begin{array}{l}\text { Stabilization of sickness fund } \\
\text { contribution rates, development } \\
\text { of incentive schemes }\end{array}$ & $\begin{array}{l}\text { Economic evaluations on } \\
\text { prevention programs and medical } \\
\text { technology }\end{array}$ \\
\hline Federal Drug Institute & Licensing of drugs & Efficacy and safety of drugs & $\begin{array}{l}\text { No experience but growing } \\
\text { interest }\end{array}$ \\
\hline $\begin{array}{l}\text { Drug Institute for Statutory } \\
\text { Health Insurance }\end{array}$ & $\begin{array}{l}\text { Positive list, comparative drug } \\
\text { cost lists }\end{array}$ & $\begin{array}{l}\text { Efficiency of drug prescriptions } \\
\text { paid by the sickness funds }\end{array}$ & No experience and little interest \\
\hline General Medical Council & $\begin{array}{l}\text { Supervise professional } \\
\text { standards and education } \\
\text { of physicians }\end{array}$ & $\begin{array}{l}\text { Physician political pressure } \\
\text { group }\end{array}$ & No experience and little interest \\
\hline Insurance doctors' association & $\begin{array}{l}\text { Negotiations with sickness } \\
\text { funds about physician } \\
\text { remuneration and drug budget }\end{array}$ & Efficient distribute of budgets & No experience and interest \\
\hline Medical societies & Treatment guidelines & $\begin{array}{l}\text { Quality assurance of physician } \\
\text { services }\end{array}$ & $\begin{array}{l}\text { No convention without a health } \\
\text { economist as keynote speaker }\end{array}$ \\
\hline Hospitals & $\begin{array}{l}\text { Internal drug list, price } \\
\text { negotiations with drug } \\
\text { companies }\end{array}$ & $\begin{array}{l}\text { High budgets and fees for } \\
\text { hospital services }\end{array}$ & $\begin{array}{l}\text { Some hospitals are very interested } \\
\text { in economic evaluations }\end{array}$ \\
\hline $\begin{array}{l}\text { Patient association (e.g. Cystic } \\
\text { Fibrosis Ass.) }\end{array}$ & None & $\begin{array}{l}\text { Influence treatment and } \\
\text { reimbursement guidelines }\end{array}$ & No interest \\
\hline Health insurers & $\begin{array}{l}\text { Negotiations with suppliers } \\
\text { about terms of care provision }\end{array}$ & $\begin{array}{l}\text { Providing comprehensive care } \\
\text { with stable cost }\end{array}$ & $\begin{array}{l}\text { Firm-based funds and local } \\
\text { sickness funds have some } \\
\text { experience and interest }\end{array}$ \\
\hline
\end{tabular}


Table 4. Ranking of targets of economic evaluation studies by department of pharmaceutical companies $(1=$ first, 2 = second, $3=$ third target $)$

\begin{tabular}{lccc}
\hline Source of study & $\begin{array}{c}\text { Health } \\
\text { insurance }\end{array}$ & $\begin{array}{c}\text { Target of study } \\
\text { Physicians/hospital } \\
\text { managers }\end{array}$ & $\begin{array}{c}\text { Government/public } \\
\text { institutions }\end{array}$ \\
\hline Medical research department & 3 & 2 & 1 \\
Product management/marketing department & 2 & 1 & 3 \\
Public relations/health economic department & 1 & 3 & 2 \\
\hline
\end{tabular}

objectives and knowledge of these institutions. In general, we believe that the experience and interest in economic evaluation of these organizations are very low, but growing.

Targets of economic evaluation studies in medical care

The focus of pharmaco-economic studies depends also on the departments of companies which suggested the study. Companies are not homogeneous institutions with uniform goals and approaches. Research departments have quite often different perspectives and goals than marketing departments. Medical research departments of pharmaceutical companies as well as the product management and marketing departments instruct health economic institutes to do pharmaco-economic studies. But also public relations departments and economic departments of pharmaceutical companies are initiating economic evaluation studies.

The different focus of the mentioned departments of pharmaceutical companies is summarized in Table 4. Medical research departments mainly try to influence decisions of government institutions, in particular the Federal Food and Drug Administration. The product management addresses their activities to the prescribers or buyers of drugs. Public relations departments, economic research groups and outcome research departments of pharmaceutical companies focus primarily on the payers, i.e. the sickness funds.

Still, the German picture on economic evaluations in medical care is confusing, because the different players in health care have different interests in economic evaluation of medical technologies. Only a small fraction of the studies is published.
Most are available only on request as internal documents (Schulenburg et al., 1994, 1995a; Schulenburg and Greiner, 1995) or are published in medical journals (Schulenburg and Schöffski, 1992; Schulenburg et al., 1995a). Only some German studies are published in international journals and hardly known in Germany (Menzin et al., forthcoming; Mapelli et al., 1994; Schulenburg et al., 1992).

The expected acceptability, objectives and targets of specific economic evaluation studies have an influence on the methods employed to analyze the cost and benefits of medical goods.

\section{Methods of economic evaluation studies in medical care}

To ease the presentation of the German experience with economic evaluation studies and to avoid detailed explanations of the various types of methods of economic evaluation studies in medical care, Table 5 presents a glossary of expressions often used in literature. In addition, the table provides abbreviations which are employed later in Table 6, a summary table of various studies conducted in Germany.

Table 6 provides an overview of studies and the employed method. All studies were conducted by the health economic group at University of Hannover. The first two and the seventh study are cost of illness studies. Those studies are experiencing a renaissance. A decade ago, the first cost of illness studies were published in Germany (Henke, 1990). These studies employed a macro design: total health care expenditures on ambulatory and hospital care were divided by the total number of physician office visits and hospital admissions and then multiplied with the corresponding numbers of visits

Table 5. Technical terms in economic evaluations

\begin{tabular}{lll}
\hline & & Definition \\
\hline Economic evaluation study & Study to evaluate health services from an economic point of view & Ebreviation \\
Pharmacoeconomic study & Economic evaluation study on drugs & CES \\
Cost of illness study & Estimating cost associated with an illness & CS \\
Cost study & Estimating treatment cost if a certain treatment is applied & CCS \\
Cost-cost study & Comparing medical cost of two or more alternative treatments & CES \\
Cost-effectiveness study & Estimating cost per one unit of clinical outcome & QLS \\
Quality of life study & Estimating quality of life effects of treatments & CUS \\
Cost-utility study & Estimating cost per unit of quality of life & CBS \\
Cost-benefit study & Estimating all direct and indirect costs and all direct and indirect benefits and measuring & \\
& them in monetary units & \\
Clinical trial-based analysis & Economic evaluation study done alongside a prospective clinical trial \\
Piggy back study & Retrospective economic evaluation study based on clinical trial data \\
Decision tree analysis & Model of real world treatment processes, estimating expected cost and expected quality \\
Delphi questionnaire & adjusted life-years & DTA \\
\hline
\end{tabular}




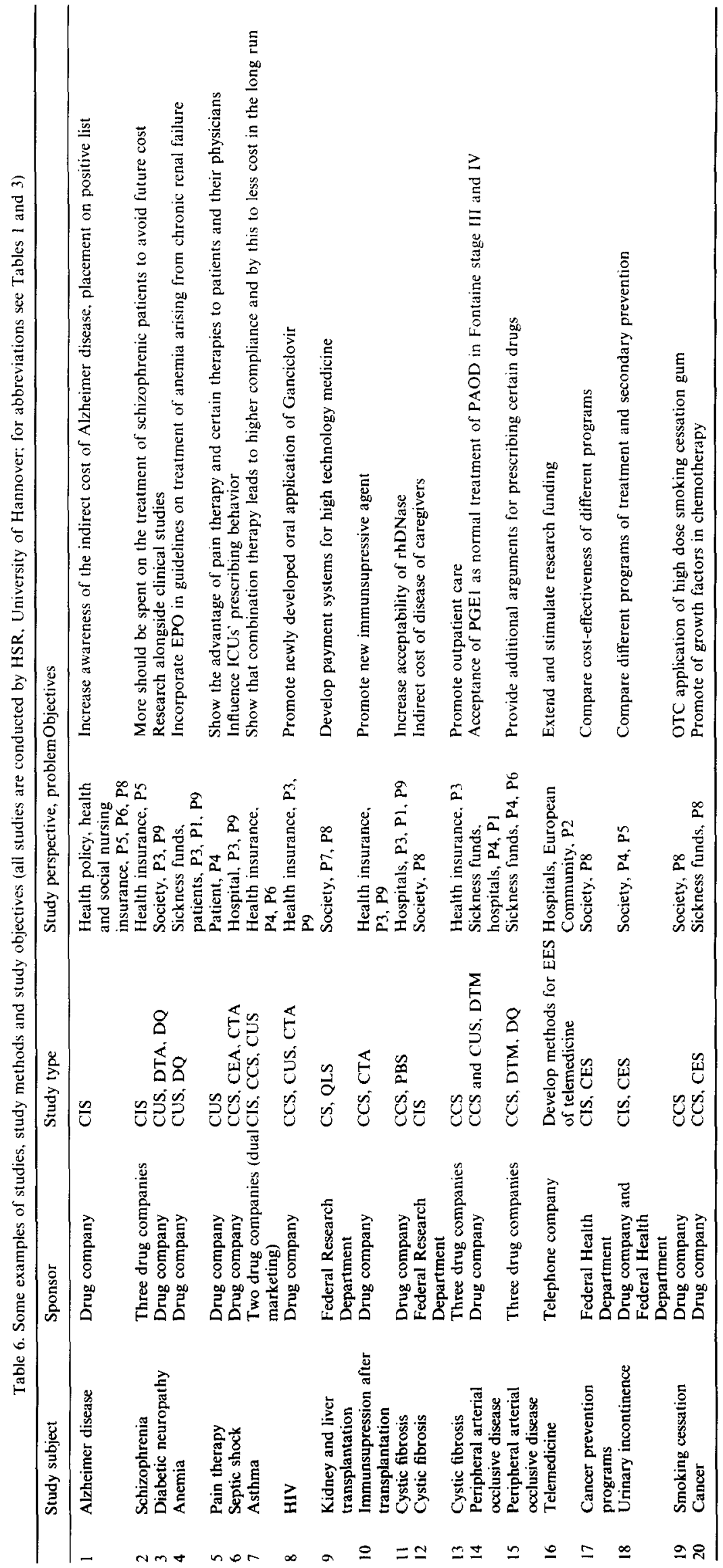


and admissions of a specific disease. In some studies indirect cost was added by employing the official sick-leave statistics. Those cost of illness studies could only provide an idea on how much was spent to treat certain diseases.

The renaissance of cost of illness studies is caused by two keywords dominating current German health policy: Priority Health Policy Goals (Prioritäre Gesundheitsziele) and Outcome Orientation (Ergebnisorientierung). Health policy analysts hope that cost of illness studies give a hint which diseases cause the highest costs and therefore are the best targets to concentrate cost-containment efforts on. In the new health policy debate, costs are not only resources used but also an outcome variable: treatment today avoids future cost of treatment.

The "second generation" of cost of illness studies employs a micro design: they take individual patient cost data, whereby all resources used to treat a patient are collected. If epidemiological data are available, individual cost data can be used to calculate the total cost of a disease in the country.

Why do pharmaceutical companies finance cost of illness studies, e.g. the cost of illness study on Alzheimer's disease (see 1 in Table 6), or the cost of illness studies on schizophrenia (2) and asthma (7)? The answer is not easy. Cost of illness studies allow them to enter the field of health economics and achieve first experiences without focusing already on specific products. Firms offering therapeutic agents for the same diseases sponsor cost of illness research jointly and base their individual studies on the study results. For instance, knowing that cost of treatment is correlated with the stage of Alzheimer's disease allows the calculation of cost savings of a drug slowing down the progression of the disease. Data from cost of illness studies are also employed to conduct German economic evaluations with international clinical trial outcome data.

The examples of German economic evaluations in Table 6 show the broad spectrum of perspectives, study types, methods and intended influence on decisions. As discussed earlier, economic evaluations are done for a great number of different reasons.

The usual study types are cost of illness (CIS), cost-cost (CCS), cost-utility (CUS) and cost-effectiveness study (CES). Table 6 contains three cost of illness studies, as mentioned above. The first one on Alzheimer's disease ( 1 in Table 6 ) and the second one on Schizophrenia (2) will be explained in more detail. In West Germany 930,000 to 1.26 million people suffer dementia. The total direct cost is estimated at 4.1 billion DM in 1987 employing a macro approach as described above. The indirect cost was estimated to be 27.2 billion DM in 1987 . In a study of 158 patients the total cost to be covered by statutory health insurance and social nursing insurance was 5384-8984 DM for mild cases
(Mini Mental State Test, or MMST>15) and 15,003-32,626 DM for severe cases (MMST < 15). The share to be covered by the social nursing insurance is positively correlated with the stage and goes from 40 to $85 \%$. This study intends to show the medical profession and the sickness funds the cost which can be saved if the progression of Alzheimer's disease is slowed down by treatment. Because there is still a lack of treatment methods of Alzheimer's disease the study should primarily increase the public attention for Alzheimer's disease and stimulate the willingness to try everything to lower its progression. The study will serve later for a cost study to analyze the potential effect of specific drug therapies.

A study on schizophrenia covers 360 patients in a prospective study whereby all resources used to treat these patients will be recorded (see 1 in Table 6). The hypothesis is that the cost will differ among institutions taking care for schizophrenic patients but will not be positively correlated with the stage of the disease. As far as I know, it is the first economic evaluation in Germany which was jointly financed by three firms. The results will be published in 1996.

Other economic evaluations are done in context of multinational studies and international marketing strategies of pharmaceutical companies (see 3, 4, 6, 8 and 20 in Table 6). For instance, this is the case for a study on growth factors (see 20 in Table 6 , Mapelli et al., 1994), HIV (see 8 in Table 6; Schulenburg et al., 1996b) or on cystic fibrosis (see 11 in Table 6) which is a chronic pulmonary disease leading to frequent coughing and infections in the airways (Menzin et al., forthcoming).

As mentioned above, pharmaco-economic studies are conducted in Germany for many purposes. That is why economic evaluations are often not only a single effort but consist of many consecutive parts where one stone after the other of a whole mosaic is studied and publicized sequentially. Two examples are presented in the next section.

\section{Strategic aspects of economic evaluation programs in medical care}

The economic evaluation program on peripheral arterial occlusive disease had three parts (see 14 and 15 in Table 6). First, a cost of illness study (CIS) on different stages of severity of the disease was performed, by selecting a sample of those patients, classifying them according to Fontaine classification. In a second part of the study, a quality of life assessment employing the EuroQoL (EuroQoLGroup, 1990; Schulenburg et al., 1996a) and a disease specific questionnaire was conducted, and again patients were classified by severity stages of disease. A third part of the study develops a decision tree disease progression model with alternative therapies. Combining all three parts of the study in a decision tree analysis (DTA) allows 
us to calculate the cost and quality of life differences (CUS) in a cohort with and without drug therapy for a five year follow-up period.

The study was mainly conducted for three reasons. First, peripheral arterial occlusive disease is a progressive disease which causes significant cost and quality of life losses in more severe stages. Second, drug therapy can slow down the progression of the disease and by this save cost in the long run. Third, and this was the major reason for conducting the study, there was a risk that certain substances employed in the treatment of peripheral arterial disease were not on the positive list of the sickness funds and are not mentioned in therapy guidelines of the angiologists' association.

The three step design of the study is typical for pharmaco-economic studies in Germany. A cost of illness study is addressed to the sickness funds which have only very poor statistics on cost classified by diseases. The quality of life study addresses the physician's and patient's perspectives. The costcost study (CCS) and the decision tree analysis (DTA) are directed to health policy, to get a drug listed on positive lists and to increase the general acceptance of a systematic management of patient careers.

Another example of an economic evaluation program is a recently finished study on asthma (see 7 in Table 6). Asthma is a chronic disease which does significantly effect quality of life. Prevalence in Germany is $5 \%$, so that about four million people have asthma in Germany. The German pneumology association (Deutsche Atemwegs-Liga) has developed guidelines to treat asthma patients. The association distinguishes between three stages of the disease.

The treatment of asthma requires treatment of acute attacks and a constant anti-inflammatory therapy. The association has discussed whether both therapies should be provided separately or in a fixed combination. Separate application has the advantage of an individual dosing. Fixed combinations have shown higher compliance rates, because the inflammatory substance is provided automatically with the one taken during acute attacks.

Companies selling fixed combinations have sponsored the economic evaluation program. The program contains several parts, a quality of life assessment (QLS), a cost evaluation (CIS) and a clinical study on patient compliance. All these activities were initiated to influence treatment guidelines of the Liga and to defend the reimbursement status of fixed combinations. The association has recently included fixed combinations as a standard therapy for certain disease stages.
Financing of economic evaluation studies in medical care

Pharmaco-economic studies are normally conducted and financed by one pharmaceutical company or supplier of a medical technology or device. In some cases studies are mutually financed by strategic alliances of drug companies marketing the same drug under different brand names (dual marketing) or close substitutes (see 1, 7, 13 and 15 in Table 6). In other cases studies are financed jointly by drug companies and governmental agencies (18). However, this is still more an exemption. HSR is currently also planning a study which is financed by a drug company and a sickness fund.

As economic evaluations in Germany, like in many other countries, have such a spectrum of objectives, estimation techniques and methods, study quality can be a problem. This is addressed by the next section.

\section{QLALITY OF ECONOMIC EVALUATION STUDIES}

With regard to economic evaluation Germany is still a "developing country". There is obviously not only less demand in the German health care system for economic evaluations of medical goods and services than in other countries with highly competitive markets or legal requirements. As mentioned above, economic evaluations in medical care are also criticized for being biased and in many cases not solidly conducted. The scientific quality of economic evaluations is often questioned, and in some cases the critics are right. Many commercial consultants do not meet minimum scientific standards. A precondition for economic evaluation studies to be accepted by decision makers in Germany in future is high quality of those studies.

The following institutions have therefore formed working groups to develop guidelines for economic evaluations in medical care:

- German Society of Pharmacology: Deutsche Gesellschaft für Pharmakologie und-therapie e.V. (GK Pharm);

- Physician's Association Working in Drug Companies: Fachgesellschaft der Ärzte in der Pharmazeutischen Industrie (FÄPI);

- Federal Association of Pharmaceutical Industry: Bundesverband der Pharmazeutischen Industrie (BPI);

- Association of Research Drug Companies: Verband forschender Arzneimittelhersteller (VFA); and

- Hannover University: North German Center for Health Services Research (HSR).

The Hannover group published the Hannover guidelines in January 1995 (HSR, 1995), which have been translated and published in English and Japanese. Recently a consensus group has published 
the German Recommendations for Economic Evaluation Studies (Hannover Konsens, 1996) which are accepted by most groups mentioned above. However, these recommendations are only a first step and have to be revised from time to time to meet the scientific development and standards in this field.

Whether guidelines will guide those who order economic evaluations, those who conduct these studies or those who use them in decision making is an open question. In any case, they will guarantee minimum standards and will also make it easier to transfer study methods and study results to other countries because the German guidelines take into account the standards already developed in other countries (e.g. Australia, Great Britain).

\section{FUTURE OF ECONOMIC EVALUATION STUDIES}

Some years ago only very few economic evaluations on medical services and pharmaceuticals were conducted in Europe and in Germany. The journal Health Economics published a bibliography on economic evaluation studies in 1992 (Backhouse et al., 1992). A total of $54.9 \%$ of the publications came from the U.S., followed by the United Kingdom (19.9\%), Canada $(5.9 \%)$ and Scandinavia $(4.6 \%)$. Only $4.1 \%$ of the publications came from the other European Union countries. The rest was going to Australia and New Zealand $(4.0 \%)$ and other countries $(6 \%)$. Ironically, economic evaluations were mostly done in the very liberal and competitive U.S. health care system and the U.K. with its centrally planned National Health Service.

However, that has changed. Although most of the studies are done in the U.S., for all major new pharmaceutical innovations pharmaco-economic studies are conducted in Europe as well, and even for older products many economic evaluations have been conducted in Europe over the past few years. In some European countries economic evaluations are needed for price negotiations, to negotiate the co-payment level, or to get drugs listed on a positive list of treatment guidelines.

In Germany economic evaluation studies are done to influence the decisions of various institutions. Experience and methodological knowledge on economic evaluation in health care are limited, and economic research in this field is criticized as unethical, useless and biased to suppliers of health services. But the German health care system is currently in a transition period from a uniform guild system to a competitive patient management system. In the old system economic evaluations were not needed and only conducted for major investments (e.g. building a new hospital such as transplantation centers; see 9 in Table 6) or as a marketing tool of pharmaceutical companies.

In Germany, all the players in medical care do prepare for a time when the power of insurers' and suppliers' associations declines and competition increases. Economic evaluations will then play a much bigger role, because economic considerations will have a larger impact on the decisions concerning resource allocation in medical care. And indeed, the future has already begun after the 1993 reform.

In addition, health policy in every country in the European Community is influenced by other countries. Reference prices for drugs first invented in Germany are now employed in other European countries, too. Price setting regulations for drugs in some countries influence the price policy of pharmaceutical companies in Germany because large price differences cause re-imports, border crossing of patients, and political pressure on drug companies. Therefore, drug companies employ an international price (Euro Pricing) and research strategy. Part of this strategy are pharmaco-economic studies which are already standard tools in some countries (France, Great Britain, the Netherlands).

However, economic evaluations will only be one effort among others to evaluate and market drugs and other medical technologies. That is why an isolated analysis of the impact of EESs on decision making is difficult and in most cases misleading.

Acknowledgements-I am grateful to Frank Sloan, Wolfgang Greiner, Christa Claes and two referees for very helpful comments on an earlier draft of this paper.

\section{REFERENCES}

Backhouse, M. E., Backhouse, R. J. and Edey, S. A. (1992) Economic evaluation bibliography. Health Economics 1, 236.

Bundesministerium für Arbeit und Sozialordnung (1995) Statistisches Taschenbuch Arbeits-und Sozialstatisitk. Order number A 129, by telephone 49-228-527-1111.

Drummond, M. et al. (1993) Economic evaluation of pharmaceuticals, a European perspective. PharmacoEconomics 4(3), 173-186.

EuroQoL-Group(1990) EuroQoL-a new facility for the measurement of health-related quality of life. Health Policy 16, 199-208.

Greiner, W. and Schulenburg, J. M. (1995) Ansätze der Lebensqualitätsmessung bei Leber-und Nierentransplantatsempfängern. In Transplantationsmedizinockonomische, ethische, rechtliche und medizinische Aspekte, ed. P. Oberender, pp. 79-114. Nomos, Baden-Baden.

Hannover Konsens (1996) Konsensgruppe "Gesundheitsökonomie", Deutsche Empfehlungen zur gesundheitsökonomischen Evaluation, Klin. Pharmakol.akt. 7(1), 53-56 [Health economic guidelines: the German perspective revisited. Pharmaco-Economics and Outcome Nen's 56, 4-6].

Henke, K. D. (1990) Die direkten und indirekten Kosten von Krankheiten in der Bundesrepublik Deutschland im Jahre 1989. In Finanzierung im Gesundheitswesen. Beiträge zur Gesundheitsökonomie, eds K. D. Henke and I. Metze. Band 10, Gerlingen, Bleicher.

Hoffmeyer, U. K. and McCarthy, T. R. (eds) (1994) Financing Health Care, Vol. 1. Kluwer, Dordrecht.

HSR (1995) Hannover guidelines für die ökonomische Evaluation von Gesundheitsgütern und -dienstleistungen discussion paper No. 10 Universität, Hannover. 
Arztezeitung 45, 10-11; Pharmazeutische Industrie 57, 4 [English version in PharmacoRessources 30/31/32].

Mapelli, V., Schulenburg, J. M., Laaser, U., Allhoff, P. G. and Rossi, F. (1994) Economic evaluation of lenograstim (glycosylated rHuG-CSF) in the treatment of inflammatory breast cancer for Germany and Italy. PharmacoEconomics 6(2), 27-35.

Menzin, J. et al. (forthcoming) A multinational economic evaluation of rhDNase in the treatment of cystic fibrosis. International Journal of Technology Assessment in Health Care.

Nagel, E. et al. (1993) Probleme ökonomischer Bewertungen medizinischer Therapieerfahrungen am Beispiel der Transplantationschirugie. Langenbecks ArchChirSuppl 139, 521-524.

Schulenburg, J.-M. (1994) Forming and reforming the market for third-party purchasing of health care: a German perspective. Social Science \& Medicine 39, 1473-1481.

Schulenburg, J.-M. and Greiner, W. (1995) Compliance bei Asthmapatienten - eine Delphibefragung zur Therapietreue bei ambulant tätigen Medizinern. Discussion Paper No. 13, Universität Hannover.

Schulenburg, J.-M. and Schöffski, O. (1992) Prostaglandin-E1-Therapie bei Patienten mit arterieller Verschlusskrankheit. Perfusion 3/5. Jg. 78-81.

Schulenburg, J.-M., Greiner, W. and Hardt, H. (1990) Soziooekonomische Evaluation des Einflusses von rhDNase auf die Kosten der Behandlung von Infektionen der Atemwege bei Patienten mit zystischer Fibrose. Medizinische Klinik 4, 220-224.
Schulenburg, J.-M., Klein, S., Piojda, U. and Schöffski, O. (1992) The cost and benefits of the use of erothropoitin in the treatment of anaemia arising from chronic renal failure. In A European Study, The German Case, eds B. Leese, J. Hutton and A. Maynard. Center for Health Economics, University of York, York.

Schulenburg, J.-M., Klimm, H. D. and Schulenburg, I. (1994) Sozioökonomische Evaluation der Behandlung einer pAVK mit vasoaktiven Substanzen. Discussion Paper No. 7, Universität Hannover.

Schulenburg, J.-M., Schulenburg, I., Horn, R., Bernhardt, T., Grobe-Einsler, R. and Möller, H. J. (1995a) Kostenanalyse der Behandlung hirnleistungsgestörter Patienten. Discussion Paper No. 14, Universität Hannover [results of pre-study published in GeriatrieForschung 1(5), 31-40].

Schulenburg, J.-M., Uber, A. Kohler, M., Andersen, H. H., Henke, K. D. and Laaser, P. G. (1995b) Ökonomische Evaluation Telemedizinischer Projekte und Anwendungen. Nomos, Baden-Baden.

Schulenburg, J.-M., Claes, C., Greiner, W. and Uber, A. (1996a) The German version of the EuroQoL Quality of Life Questionnaire, Plenary Meeting Barcelona 1995. Discussion Paper, Institut Universitari de Salut Pública de Catalunya.

Schulenburg, J.-M., Wähling, S. and Stoll, M. (1996b) German Health Economic Cost Evaluation on Oral Ganciclovit in Treating Cytomegalovirus Retinitis. PharmacoEconomics 10(5), 522-530.

Sloan, F. (ed.) (1995) Valuing Health Care. Cost, Benefits, and Effectiveness of Pharmaceuticals and Other Medical Technologies. Cambridge University Press, New York. 